\title{
Entrevista a la Doctora María Elena Mansilla Y MEJÍA ${ }^{1}$
}

ABRIL USCANGA BARRADAS

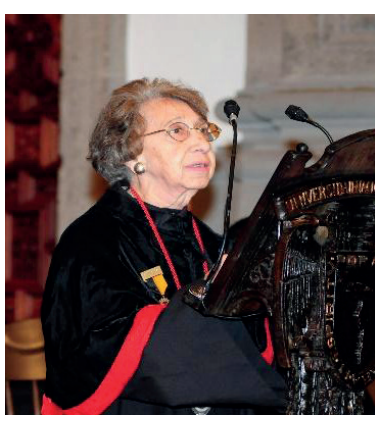

María Elena Mansilla Y Mejía obtuvo los grados de Doctorado en Derecho, Maestría en Criminología y Especialidad en Derecho Constitucional y Administrativo. Es Catedrática en la Licenciatura de la Facultad de Derecho de las asignaturas de Derecho Internacional Privado I y II y Teoría General del Estado, de Derecho Competencial y Relaciones Económicas Internacionales en la División de Estudios de Posgrado. Es coautora del Manual Práctico del Extranjero en México; es autora del Juicio de Amparo en Materia Civil; de los Glosarios de Derecho Civil; y Derecho Internacional Privado; del primer curso de Derecho Internacional Privado y dos volúmenes de Derecho Internacional Privado II que forman parte de la enciclopedia realizada por la Facultad de Derecho. Fue Recipiendaria del Premio Lombroso, de las Cátedras Especiales César Sepúlveda, Antonio Díaz Soto y Gama, González Uribe, Reyes Heroles y de la Cátedra Extraordinaria José Castillo Larrañaga. Fue Recipiendaria de las Medallas: Prima de Leyes Instituta

${ }^{1}$ Este documento constituye una transcripción de la entrevista realizada. Se ha revisado sin alterar el estilo coloquial propio de una conversación, considerando que esta característica enriquecería el texto que se presenta al lector. La entrevista fue realizada con la colaboración de Andrea Valencia Bermúdez y Brenda Olalde Gómez. 
2002-2003, Sor Juana Inés de la Cruz 2008 y Vasco de Quiroga 2011. Fue Homenajeada por la Academia Mexicana de Derecho Internacional Privado y Comparado en 2009, en la Universidad Autónoma de Baja California y la Universidad de San Diego. USA, Es Asesora Externa Honoraria de la Secretaría de Relaciones Exteriores y Delegada por México ante la Conferencia de la Haya de Derecho Internacional Privado. Es miembro de número de la Academia Mexicana de Derecho Internacional Privado y Comparado Fue consejera del H. Consejo Técnico de la Facultad y miembro del Consejo Universitario durante 2007-2011 y tuvo el altísimo honor de ser elegida para dar el discurso de los 100 de la UNAM en representación de los maestros e investigadores. Actualmente es Directora del Seminario de Derecho Internacional de la Facultad de Derecho e Investigadora nivel II del programa del Sistema Nacional de Investigadores del CONACYT.

Entrevista a la Doctora María Elena Mansilla y Mejía

Abril Uscanga Barradas: Doctora muy buen día, es un placer estar con usted. Muchísimas gracias por habernos aceptado esta entrevista de la Revista del Programa de Posgrado en Derecho.

María Elena Mansilla y Mejía: Muy buenos días Doctora Uscanga, me da mucho gusto y realmente me siento muy honrada de haberme considerado para la entrevista de la Revista del Posgrado en Derecho, de la que es usted directora.

AUB: Le agradezco nuevamente. Nos gustaría empezar conociendo un poco acerca de usted, queremos preguntarle en relación a su formación académica, ¿Cuáles fueron sus motivaciones para estudiar derecho?

MEMM: Mi familia es de abogados, yo escuché "derecho" toda mi vida, siempre me interesé en la plática de mis padres y de un tío que es el que inicia la estirpe de abogados, por ello siempre viví el derecho. Hubo una época en la que me interesaron las matemáticas, y pensé ir a ingeniería ipero no!, realmente mi vocación fue el derecho. 
AUB: Doctora, ahora que nos comenta acerca de la motivación de su vocación, quisiéramos conocer un poco acerca de su trayectoria como estudiante. Podría comentarnos ¿cómo era la vida universitaria?, ¿cómo era estudiar en la Facultad de Derecho?

MEMM: Era maravilloso, yo soy de la generación del año cincuenta y tres, la Generación del Cuarto Centenario. En aquella época el estudio era anual, mi primer año lo cursé en San Ildefonso, realmente fue muy emocionante, porque ahí estudiaron mis padres; los compañeros eran muy educados, muy correctos y nos cuidaban, a los de primer año les decían perros y les cortaban el cabello, y mientras lo recuperaban los jóvenes tenían que usar una boina vasca. Al siguiente año se inauguró Ciudad Universitaria y dejamos San Ildefonso, aunque realmente nos quedaba lejísimos, los primeros días los alumnos tuvimos que caminar desde el monumento de Álvaro Obregón. Los maestros también tenían problemas para llegar, algunos tomaban el autobús y nos encontrábamos con ellos, en aquellos años no era fácil tener carro. Fue una época muy distinta, donde la relación amistosa maestro-alumno, no existía. No sé si fue por el cambio de San Ildefonso a Ciudad Universitaria, el maestro para nosotros, era algo especial, se le escuchaba embelesado, tuve maestros extraordinarios, nunca me acerque a preguntarles alguna duda, yo la resolvía porque no existía esa relación que considero necesaria y que actualmente sí se da.

Teníamos exámenes orales que empezaban y terminaban a la hora que el maestro decía, yo llegué a salir de CU a las doce o una de la mañana, teníamos la fortuna de que los jóvenes eran muy amables, incluso en ocasiones nos acompañaban a la casa, era otra época. La casa de usted estaba en Linda Vista, yo tomaba el camión en la Av. Montevideo, me bajaba en la Alameda y ya estaba la cola que era exclusivamente de estudiantes, era un ambiente totalmente estudiantil de jóvenes de ingeniería, arquitectura, derecho y 
filosofía, el camión se llenaba y no se admitían personas paradas, imagínese sino era maravilloso, Insurgentes no tenía semáforos y en quince minutos llegaba a CU.

AUB: En ese entonces ¿cómo era Ciudad Universitaria?, ¿Cuál es la diferencia entre el ayer y el hoy?

MEMM: La facultad no ha cambiado mucho, se ha movido el barandal o los vidrios o cosas así, salvo, la desaparición de los seminarios, los seminarios creo que usted ya no los conoció, eran bibliotecas especializadas, en el seminario de internacional sólo había libros de internacional, el de Teoría del Estado sólo tenía libros de Teoría del Estado, en esa época eran catorce seminarios, ahora son diecisiete; se trabajaba muy bien, el director era muy riguroso, pese a ello siempre nos atendía con amabilidad. Había maestros adscritos a los seminarios, era fácil platicar con ellos; teníamos un bibliotecario en la mañana y uno en la tarde, una secretaria en la mañana y una en la tarde; eran puntos de reunión para investigar o para hacer la tesis, en este caso nos exigían tiempo de permanencia, aunque en realidad mucho de ese tiempo era de convivencia, finalmente nos veíamos obligados a cubrir horas de estudio ya que teníamos los libros a la mano. La desaparición de los seminarios fue muy triste, ocurrió en 1992, el Doctor Serrano intentó instalarlos nuevamente pero siempre tuvo obstáculos.

AUB: ¿Qué diferencias existían con respecto a la enseñanza?

MEMM: En ese tiempo no podíamos comprar libros, éramos estudiantes y pagábamos colegiatura, se pagaban doscientos pesos, era mucho dinero, imagínese que le hablo de los años cincuenta. Se podía pagar en dos partes, una al inscribirse y la otra al concluir el curso, si no se cubría, el nombre no salía en la lista de exámenes, no había extensiones. Los maestros eran extraordinarios, realmente fue una época maravillosa con verdaderas clases magistrales, actualmente se critica ese sistema, sin embargo, la clase conferencia 
nos permitía escuchar a los profesores, se nos quedaba grabada la voz del maestro y cuando se estudiaba el tema se escuchaba nuevamente su voz. Entiendo que las cosas tienen que cambiar y uno se tiene que adaptar a las transformaciones, pero la clase tipo conferencia, para mí fue excelente.

AUB: Hay cosas que han cambiado por supuesto de ese momento a este. Coméntenos en relación a la población femenina, imagino que era un porcentaje menor al del actual.

MEMM: ¡Infinitamente menor! toda mi generación exactamente fuimos mil, de los cuales 50 éramos señoritas, nos formábamos por grupitos, era un ambiente muy agradable, incluso hasta la fecha eventualmente nos reunimos. La población era infinitamente menor, ahora los pasillos son insuficientes, el cambio de clase es terrible, antes era tranquilo, es evidente que poco a poco creció la matrícula de los alumnos.

AUB: Doctora y ¿cuál cree usted que haya sido el mayor reto que enfrentaron las mujeres en aquel momento?

MEMM: Yo nunca sentí ningún problema, tal vez sería porque estaba acostumbrada al sistema, porque los compañeros eran muy respetuosos y los maestros también. En la casa de usted mi padre era una persona que nos daba libertades controladas, entonces, nunca sentí ni me enteré de una falta de respeto hacia una joven, imposible pensar en el "acoso", esa era una palabra desconocida para nosotros, y si existía seguramente fue muy discreto, ahora las condiciones son diferentes, la mentalidad cambia como cambia la moda, pero realmente nunca, que yo supiera, sufrió alguna de nosotras una molestia por parte de otra persona.

AUB: En este sentido doctora, ¿qué profesores o autores durante su formación marcaron su vida profesional?

MEMM: Tuve tres maestros fundamentales: la Doctora Arnaiz que me dio Teoría General del Estado, era una mujer muy adusta 
pero increíblemente responsable, inicialmente tuvimos un maestro de Teoría del Estado que, no menciono su nombre, pero nunca asistía, nos quejamos con el director y finalmente lo resolvió con la maestra Arnaiz el mes de septiembre y en octubre comenzaban los exámenes. La maestra puso como condición para aceptar la clase impartirla de siete a ocho y de once a doce que era la hora en que terminaban nuestras clases, lo planeó así para darnos el curso completo, aclaró que solo de esa forma tomaría el grupo, eso a mí, definitivamente me marcó dentro de la responsabilidad y la entrega al trabajo, en aquella época la maestra era joven y sus niños estaban pequeños, aún así puso la condición, el director la aceptó y nos dio el curso completo, nos examinó con el doctor Serra Rojas y el resultado creo que fue bastante favorable. Otro maestro fue el Doctor Burgoa, el me hizo enamorarme del amparo, de las garantías individuales y del derecho a la libertad, era fascinante su clase, al terminar la parte de las garantías recibía una verdadera ovación, eran aplausos por la admiración que nos causaba, se exaltaba, se inflamaba al impartir la clase, nos conocía a todos de nombre y le aseguro que fácilmente éramos cien; otro maestro fue el Lic. Carlos Cortés Figueroa, él nos daba derecho procesal, ese maestro era secretario de acuerdos en la Corte, era terrible pero era un gran maestro, yo todavía escucho su voz cuando doy la parte de procesal en mi curso de internacional privado, siempre nos decía "nunca se renuncia a la acción, se renuncia a la instancia" y algo invaluable eran los principios jurídicos, fue un maestro extraordinario. Cada maestro me enseñó algo distinto, me gustaba Cortes Figueroa por la disciplina y la forma de exigir, Burgoa por la impartición de sus clases y su entusiasmo, y la maestra Arnaiz por su responsabilidad. Quiero mencionar también a la maestra González, de ella aprendí como dirigir un seminario, y aunque le decían la "generala" era una persona de un corazón verdaderamente generoso, tuve una bonita 
amistad con ella y cuando falleció lo sentí muchísimo.

AUB: Doctora, retomando un poco lo que hemos comentado acerca de esos momentos, ¿cuándo decide usted dedicarse a la academia?, quién o cuál fue ese puente que la hace quedarse en la Facultad de Derecho, ¿qué la motivó?

MEMM: A mí no me motivaba la enseñanza, me gustaba el litigio, mi padre fue litigante y mi madre también, por eso la clase de procesal que nos impartía Cortes Figueroa para mí era una clase fundamental. Empecé a trabajar en el Departamento de Asistencia Jurídica de la Secretaría de Salubridad, así se llamaba entonces, un maestro español Arilla Bas puso un letrerito en la Facultad, las cuatro amigas fuimos y nos recibieron, y claro, cómo no nos iban a recibir si no nos pagaban, nos trataban amablemente, el jefe del departamento nos recibió y siempre platicaba con nosotras, después supe era tío del doctor Carvajal quien fue el director de la Facultad. El jefe de asistencia era un hombre ya grande para nosotros, tendría aproximadamente entre cuarenta y cuarenta y cinco años, era muy amable, nos enseñó y nos toleró mucho porque además, como jóvenes éramos muy ruidosos y alegres, ahí me introduje al litigio. Después me pasaron al jurídico de Salubridad, posteriormente fui Juez Calificadora de la Oficina Calificadora de Infracciones del Distrito Federal y litigué un tiempo, formamos un despacho entre compañeros, finalmente lo dejamos porque nos absorbía más el trabajo de salubridad, me casé y me retiré, con el tiempo regresé pero ahora a la docencia la cual siempre me asustó. Hay una preparatoria cerca de la casa de usted, mi esposo daba clases ahí pero tuvo que dejarlas por lo que yo las tomé, y volví al estudio, era verdaderamente horrible, me la pasaba todo el día estudiando porque yo me decía: "y si no les enseño, y si no soy clara", era una serie de dudas espantosas, ahí me inicié en la docencia y posteriormente entré a trabajar al Seminario de Teoría General del Estado. 
AUB: ¿En qué año doctora?

MEMM: Entré con la Dra. Arrnaiz en el año ochenta y tres, antes trabajé en la Coordinación de Humanidades con el Dr. Pérez Nieto de finales del setenta y nueve al ochenta y uno, estuve vacante un tiempo y en el ochenta y dos vine a un examen profesional, me encontré a la maestra Arnaiz, platiqué con ella y me dijo que fuera a verla, entonces percibí los cambios, ya no me hablaba de usted, me hablaba de tú, y entré a trabajar con ella al Seminario. La materia de Teoría del Estado siempre me gustó, máxime que admiraba a la maestra. Me consiguió una cita con el Secretario General, quien me ofreció la clase de Internacional Privado y de ahí me seguí, ese era mi destino definitivamente, posteriormente me dieron la clase de Teoría del Estado. La verdad yo no fuí una maestra por vocación, pero ahora lo soy por convicción, me gusta y me divierto en mis clases.

AUB: Doctora ¿cuál fue esa transición en donde usted se convierte en directora del seminario de derecho internacional?

MEMM: Eso fue triste porque ocurrió cuando murió el maestro García Moreno, me habló el Doctor Carvajal y me dijo: "maestra le ofrezco el seminario de internacional", a lo que yo respondí "iay no, no, no!, esa es mucha responsabilidad, yo estoy muy a gusto en Teoría del Estado", y me respondió "le hablo en serio, le ofrezco el seminario", lo que me hizo contestarle: "bueno ¿cuándo le debo resolver?", me dijo: "Mañana, a las once máximo"; Era sábado, el domingo a las once en punto le hablé y le dije: "está bien, acepto".

AUB: ¿Cuántos años tiene ya como directora?

MEMM: Nada más cuéntele, fue antes de la huelga en el noventa y nueve, desde el noventa y nueve estoy aquí.

AUB: Yo creo que con gran mérito doctora porque llevar un seminario no es una responsabilidad menor, al contrario, es un trabajo de mucha dedicación. 
MEMM: Eso se lo debo a la maestra González, era de las personas que decían: las cosas debían hacerse para tal día y ese día tenía que estar, nos llamaba para ver cuántas tesis llevábamos y las revisaba. Realmente fue la maestra González la que me enseñó cómo dirigir un seminario, aunque yo entré con la maestra Arnaiz, ella cerraba su puerta y se ponía a estudiar, eventualmente nos llamaba y nos preguntaba, era muy rígida para recibir tesis y un poco violenta con los muchachos. En cambio la maestra González nos recibía, nos platicaba, hicimos amistad, en fin, era bonito y aprendí su rigidez y su exigencia para que las cosas que tuviéramos que entregar hoy debieran estar para ayer, porque hay que revisar que queden bien.

AUB: Ahora bien, ya hablando acerca de su labor como profesora, que va a la par de la dirección del seminario desde el noventa y nueve, ¿Cuál ha sido el mayor reto que ha tenido como profesora?

MEMM: Qué le diré, diario es un reto, para uno es asistir a un examen con los alumnos, cuando nos plantean una duda, pienso que mientras más tiempo se imparte la clase lejos de resolver las dudas, más aumentan, el reto lo tenemos diariamente. Pero un reto en particular como profesora creo que fue en los primeros semestres que empecé a dar clase, yo iba con mucho miedo, empecé ayudando a la maestra Arnaiz en su clase de Teoría del Estado, la materia me gusta, y antes los muchachos eran más activos, participaban más, me inicie en la clase en una preparatoria, donde el problema era la disciplina, realmente no tenían mucha imaginación para plantear preguntas, aquí es diferente, el reto es diario hasta la fecha.

AUB: Doctora, con las nuevas generaciones la situación ha ido cambiando, la relación profesor alumno ha ido variando como usted ya lo ha comentado. ¿Qué cree que es lo que define actualmente a un alumno de excelencia? 
MEMM: La responsabilidad. Yo sostengo que un alumno responsable no necesita más, con responsabilidad estudia, con responsabilidad cumple, con responsabilidad llega a tiempo, con responsabilidad sigue las reglas. Sí, la responsabilidad es definitiva.

AUB: En algún momento todos la conocemos porque no únicamente busca brindar información y conocimientos sino porque busca formar a los alumnos como abogados, tener la vocación como abogado, tener la visión como abogado, pensar como abogado y verse como abogado. En gran medida tal vez eso se ha ido perdiendo y no es una constante en todos los profesores de esta facultad.

MEMM: Yo siempre trato de que recuerden, que el abogado tiene tres grandes cualidades: la puntualidad, la presentación y los conocimientos.

AUB: En ese sentido doctora, ¿cree que las nuevas generaciones tengan nuevos retos?, es decir, el nuevo abogado que se está formando probablemente se enfrenta a una situación o condiciones diferentes a las que se enfrentaban hace algunas décadas. ¿A qué se enfrentan los alumnos terminando su formación en estas aulas?

MEMM: Considero que el problema al que se enfrentan, es que no están muy conscientes de su responsabilidad, y que las exigencias cada vez son mayores, generalmente se dice que hay desempleo, yo insisto que si están preparados no hay desempleo, si les dan una oportunidad salen adelante, pero si no están preparados aunque les den la oportunidad no lo van a lograr, considero que ese es uno de los retos; y que, más bien no es reto, sino un gran problema, es la tecnología, es maravillosa, es estupenda, pero los jóvenes han perdido capacidades, ya no recuerdan el número de teléfono de su casa, tiene que buscarlo en el celular, han perdido la memoria. Les digo, "es que muchachos no van a saber llegar a su casa y eso no debe ser, la tecnología es estupenda pero úsenla para lo que sirve", nunca van a un libro, todo lo quieren sacar de internet yo no digo 
que sea malo, es bueno sobre todo si no se logra disponer del libro, se recurre a internet, pero tenemos una biblioteca muy grande, está la Biblioteca Central y además es bueno que vayan formando su propia biblioteca. La tecnología mal utilizada es un grave problema al que se enfrentan y si no se dan cuenta van a perder capacidades. La situación es que cuando es necesaria la reflexión y el análisis en la solución de un problema, les cuesta trabajo analizarlo y resolverlo, la reflexión y el raciocinio lógico no lo saben aplicar, hay que incrementar la reflexión y la memoria, se dice que la carrera no debe ser de memoria, lo que es verdad pero tienen que estudiar porque si entendieron el problema y no lo repasan se les va a olvidar, hay que utilizar la memoria porque es uno de los elementos fundamentales con los que nacemos, si no lo utilizamos es como si no utilizáramos los pies, pues no vamos a poder caminar, y si no utilizamos el cerebro, se vuelve inútil, así que, sí tenemos esas facultades innatas hay que desarrollarlas. El raciocinio y la reflexión son indispensables en nuestra profesión que, por supuesto son necesarias en todas, pero en la nuestra mucho más, al respecto les digo a mis alumnos que un cuerpo humano va a tener siempre doscientos huesos, si es que esos son lo que tiene, no van a cambiar, las meninges van a estar en el mismo lugar y serán siempre tres, los dedos van a ser los mismos a menos que mutemos, pero tales cambios ya no los vemos, en tanto que los asuntos que se les presenten van a ser diferentes y van a tener que estudiarlos, analizarlos y razonarlos, porque una letra les puede cambiar todo el sentido.

AUB: Estoy de acuerdo totalmente con respecto a la reflexión y razonamiento. Ahora bien, ¿'ha visto o ha podido percibir en los alumnos alguna virtud? Especialmente pensando en que están inmersos en la tecnología, en que ellos buscan formas distintas para la resolución de los problemas jurídicos. ¿Tendrán alguna virtud que podamos exaltar en ellos? 
MEMM: Si, una virtud que en cierta forma descubrí, lo hice para integrar al grupo, recientemente pude identificarla al proponer una mañana literaria, en ella hubo mucho talento, tocaron guitarra, teclado, declamaron, inventaron cuentos e hicieron teatro. Realmente tienen sentido humanista, eso me dio muchísimo gusto, solo les dije, organicen una mañana literaria y me dicen qué día quieren que la hagamos, claro que debe de ser a la hora de clase, en dos días me dijeron, maestra, para tal día ya estamos preparados, fue algo increíble, tienen una capacidad de organización, de talento artístico y literario verdaderamente digno de admirar. La cooperación que tuvieron entre ellos fue un gran trabajo de equipo, orden y respeto entre ellos.

AUB: Eso resulta sumamente interesante porque de alguna forma se deja atrás la idea del abogado que solamente conoce leyes.

MEMM: Decir que solo se conoce de leyes es una tontera, porque lo que deben tener es criterio, saber encontrar el problema, meditarlo, desarrollar los argumentos y resolverlo. Vivimos en una inseguridad jurídica, en la Constitución acaban de cambiar cuatro artículos hace quince días y la gente pregunta: ¿ya te aprendiste los artículos? Eso es una tontería, la ley debe entenderse no memorizarse.

AUB: Doctora y ahora usted que tiene una gran trayectoria en esta universidad y especialmente conocemos que hace poco le acaban de dar un reconocimiento por parte del Rector destacando su labor académica como parte importante de esta comunidad jurídica pero también de esta universidad, ¿qué ha representado para usted este reconocimiento que le han dado? Si pudiera platicarnos acerca de él, y en general, ¿qué representa para usted la UNAM?

MEMM: Bueno, voy a contarle una anécdota que cobra sentido con el paso de los años: a un maestro en una ocasión lo asaltaron y en lugar de irse a su casa vino a la universidad, yo recién había 
ingresado a dar clases, me lo encontré, y él me dijo: "me vine a mi casa", yo pensé que estaba exagerando, ahora lo entiendo y es cierto. Yo aquí estoy muy contenta, platico con las maestras, con los maestros, con los alumnos y en general con nuestra comunidad. La universidad y la facultad ahora son mi segunda casa, cuando el maestro lo dijo no lo entendí, pero esta es mi otra casa, yo aquí vivo, llego, platico, disfruto y luego me encierro a trabajar, si llama un maestro de inmediato lo atiendo, si llega un alumno lo mismo, porque me gusta mi trabajo. Aprendí a disfrutar la docencia, y ahora digo lo que decía ese maestro, "esta también es mi casa".

AUB: Podría comentarnos un poco acerca del motivo por el que le entregaron el reconocimiento, un poco acerca de su trayectoria académica, ¿cuál es la relevancia que ellos vieron con respecto a usted?

MEMM: Realmente no creo tener merecimientos, tengo aquí muchos años que he dedicado a mi trabajo, por supuesto que para mí ha sido un gran honor haber recibido ese reconocimiento, que haya estado el rector presente, es algo muy especial, fue un momento muy significativo.

AUB: ¿Cuántos años tiene de docencia doctora?

MEMM: Estoy por cumplir los treinta y nueve, en octubre.

AUB: Y la verdad es que todos queremos que usted siga aquí hasta que usted lo decida por supuesto, pero, Doctora ¿ila intención es continuar aquí en el seminario?

MEMM: Continuar en el Seminario no depende de mí, sí la Facultad es mi casa, ¿a dónde iría?, bueno, a la casa de usted por supuesto, pero esta también es mi casa. La verdad no podría encerrarme de nuevo, estuve mucho tiempo en ella, había motivos muy importantes para estarlo, la formación de una familia, pero ese trabajo ya concluyó, por lo tanto sigo aquí. 
AUB: Y nosotros estamos muy contentos de que así sea doctora, que sea por todo el tiempo que usted decida, pero deseamos que sea infinitamente posible tenerla aquí.

MEMM: Mientras yo siga subiendo y bajando escaleras voy a seguir aquí, eventualmente tomo el elevador pero mi límite es: el día que ya no pueda subir las escaleras, aclaro, que no las pueda subir, mas no que no las quiera subir, eso es otra cosa, ese día será mi límite.

AUB: Pasando a los temas en los que nosotros la conocemos como una experta del Derecho Internacional, en particular diría yo, si me lo permite, del Derecho Internacional Privado.

MEMM: Así es, de Derecho Internacional Privado.

AUB: Quiero permitirme hacerle algunas preguntas en torno al Derecho Internacional ¿cuáles consideraría usted que son los mayores desafíos que enfrenta la política exterior mexicana actualmente?

MEMM: De los desafíos que enfrenta la política exterior mexicana digamos que yo la podría clasificar en tres aspectos: relativo a las personas, es decir, a los problemas que tenemos con la migración, el relativo al comercio internacional con el problema de la inversión extranjera y el tercer problema es el político. Los iuspublicistas insisten en que la soberanía no existe, yo sostengo que mientras haya fronteras el derecho internacional público existe y la soberanía debe existir, considero que uno de los grandes problemas en los que México debe pensar es en mantener su soberanía. Sabemos que existe la globalización, que ya tenemos compromisos con muchos países por los tratados de libre comercio, que tenemos en el norte una persona bastante difícil, está también la invasión migratoria, en esto México debe mantener su postura de país pacífico, noble, de país que recibe pero con control, eso por el aspecto político. En cuanto a la cuestión personal, creo que el problema de los migrantes es muy triste, viene toda clase de personas, no sabemos quiénes 
son, no vamos a decir que son delincuentes como dicen que son los mexicanos que van a Estados Unidos pero también sabemos que algunos pueden tener antecedentes penales, por lo tanto debe haber un control. Sí, pobres migrantes, se les debe ayudar, sin embargo primero hay que cuidar la seguridad del país, se les debe atender dignamente y no meterlos a esas inmundas estaciones migratorias, la Ley de Migración en ese sentido es generosa, no tenía todas esas ventajas para los inmigrantes la Ley de Población. Son personas, hay que respetarlas no debemos maltratarlas, hay que darles dentro de lo posible un buen trato y regresarlos a su país, a los que deseen quedarse debe ser de acuerdo con nuestra legislación de migración, se debe aplicar la Ley pero no podemos dar a un extranjero más de lo que le daríamos a un mexicano porque aquí también tenemos millones de mexicanos en pobreza extrema, por lo tanto es necesario reflexionar sobre nuestras posibilidades.

AUB: Doctora ¿qué debería México considerar para una nueva modificación en torno a la Ley de Migración para regular eficazmente el régimen migratorio?, esto hablando específicamente de la relación que tenemos con nuestro vecino del norte, con Estados Unidos de América, ya que la política arancelaria depende actualmente de la política migratoria, es decir, la política migratoria está generando cambios en otras políticas debido a las nuevas caravanas que han pasado por México rumbo a Estados Unidos de América, toda vez que México es paso obligado, ya sea por tierra, por mar o por aire. ¿cuál es la perspectiva que debería tener México con respecto a una posible modificación en las leyes o una perspectiva tal vez un poco más a futuro con respecto a las políticas migratorias?

MEMM: En realidad, tal como está la ley está bien, no creo sea necesario hacer cambios, la ley contempla la posibilidad del control migratorio y el problema es que estas caravanas, tal y como usted las llama acertadamente, es que son miles de personas que ingresan 
al territorio, y deben ser controladas, eso es indispensable, no pueden decir que están en su casa porque no lo están, van a estar en su casa si se someten a las reglas de aquí, porque es un tanto peligroso el recibir así nada más sin hacer una entrevista, platicar con ellos, el por qué vienen, en México la ley es muy generosa, viene la familia, la mamá o el papá, dos, tres niños, la abuelita, y no los separan, los regresan a todos juntos y si se acogen a la ley y deciden quedarse, pueden hacerlo, debido a que se les ofrece legalizarlos, pero hay que controlarlos. Es necesario implementar una política efectiva de control, no policial, pero sí de control humanitario, que se proteja a las personas, que no se les maltrate que no se les golpee, que no se les pida dinero pero que sí se les controle.

AUB: En ese mismo sentido doctora, ¿cree que México ha tenido una adecuada reacción en torno a la política migratoria?, no solamente me refiero por la frontera sur sino también por la frontera norte ya que México ha decidido de alguna forma el acoger también a los migrantes que Estados Unidos ha rechazado o que todavía no acepta en su territorio, entonces México se ha conformado como un país de tránsito donde una parte de los migrantes incluso ni siquiera tienen intenciones de quedarse.

MEMM: En efecto, generalmente no pretenden quedarse.

AUB: ¿Cómo podría México afrontar este problema desde una perspectiva distinta o desde una política distinta? que por supuesto tendría consecuencias en materia de comercio exterior. ¿Usted considera que esto implicaría reformular las políticas en materia de comercio exterior?

MEMM: Realmente la cuestión del comercio exterior es una complicación grave porque hemos celebrado muchos tratados de libre comercio y nos dedicamos a negociar con Estados Unidos, decimos que es el mayor comprador y vendedor que tenemos, la pregunta es: entonces ¿para que celebramos tantos tratados de libre 
comercio? eso por lo que toca a la cuestión comercial. En cuanto al problema de la inversión extranjera, debe ser complementaria y estimulamos a la inversión extranjera para que venga a cubrir todos nuestros nichos productivos eso no está bien, y no solo eso, sí la inversión extranjera cubriera todos los vacíos, la inversión mexicana sería mínima y dependeríamos del extranjero. Imaginemos que a la empresa el gobierno le pida que aumente los sueldos, si la empresa se niega y amenaza con irse, se pone en riesgo la continuidad de la empresa en el país, y se arriesgan los empleos que genera.

El país es muy complaciente con la inversión extranjera, principalmente por la generación de empleos, considero que no se debe recibir indiscriminadamente, es verdaderamente doloroso lo que pasa con las compañías canadienses que explotan las minas y sale más metal precioso del que se fue con la colonia, México es tan maravillosamente rico que tuvimos siglos de explotación y ésta aún continua. Cómo es posible que quienes trabajan en las minas vivan y mueran como esclavos y nuestra riqueza minera se vaya. La inversión extranjera es buena ¿hasta dónde es buena? eso es muy importante; estudiarlo y calcularlo, no tenemos maquinaria por los tratados de Bucareli, no podemos construir maquinaria pesada, somos solo ensambladores, entonces busquemos otro camino, no demos las minas al extranjero, si los mineros van a ser del pueblo, que el inversionista sea mexicano o el Estado.

AUB: En esa vía doctora, ¿México podría tener otro socio comercial tan fuerte como Estados Unidos?, digamos, ¿podríamos voltear a ver a otro socio comercial?

MEMM: Claro que sí. Podríamos si nos uniéramos con América del Sur y América del Centro, seríamos una potencia. Lamentablemente no nos quieren en América del Sur porque nos ven dirigidos hacia el norte, México se molestó porque no lo invitaron a la UNASUR, cómo nos van a invitar si además de tener relaciones 
con Estados Unidos, lamentablemente en ocasiones, se aceptan situaciones en las que parece que perdemos dignidad.

AUB: Usted ha participado en algunas conferencias en materia de Derecho Internacional Privado, especialmente me refiero a la de la Haya como representante, ¿qué fue lo que se discutió?

MEMM: Participé en todas las reuniones plenarias, telefónicas y vía internet de la Convención de Recuperación de Alimentos para los Niños y otros Miembros de la Familia, fueron seis años de negociaciones y finalmente concluyó la convención. Es un ambiente muy respetuoso, participaron en esa época 82 países, ahora son diez más. Las propuestas que presentan los Estados se respetan, nadie las puede cambiar a menos que el país que la propuso lo acepte. Generalmente se crean una o dos comisiones con fines específicos, en este caso fueron tres: de redacción, en realidad no fue de redacción, sino de armonización de todas las propuestas, es un trabajo realmente muy pesado, se revisan los dispositivos punto por punto, uno por uno, es un trabajo académico internacional, no hay grupos de presión. La primera vez que fui a La Haya había sólo una persona de argentina enviada por la embajada y yo de México, cuando concluyó la negociación en 2007, ya asistieron representantes de Colombia, Venezuela, Salvador y Argentina. Las discusiones son muy profesionales, la mesa que dirige el secretario o el primer secretario adjunto es muy respetuosa, es un ambiente realmente académico, la Secretaría de Relaciones Exteriores me envió y lo único que se me indicó fue: México nunca propone una reserva aunque sea necesaria, pero si se adhiere, de esta forma logré que mediante la adhesión a una reserva y a una declaración interpretativa, la convención no afectará el orden público del derecho mexicano. Ahorita está nuevamente en México la discusión del convenio, es un documento concluido en el dos mil siete y a la fecha no pasa al Senado para su discusión, el problema es que no hay Autoridad Central para asumir el compromiso, conforme a derecho le corresponde al DIF. 
En las negociaciones lamentablemente hubo una situación molesta debido a que Estados Unidos declaró que solo firmaría acuerdos bilaterales, la oposición fue generalizada de México, Inglaterra, España, Francia, Alemania unánimemente se consideró que era una posición indebida por tratarse de una convención universal, los niños son universales no son solo de Estados Unidos, y del país con quien Estados Unidos eligiera firmar, esto crea una situación muy significativa y claro, después de eso el ambiente se enrareció un poco, ese es el problema con Estados Unidos, asiste, discute, trata de convencer, se lo acepta dentro de lo posible, lo que propone y después no firma.

AUB: Me parecen muy interesantes estas conferencias, ha sido una gran decisión que usted haya sido representante por México.

MEMM: Fue un gran honor para mí que me eligieran. He participado también en la Convención sobre Principios de la Haya; Contratación Internacional y la última que fue sobre Reconocimiento y Ejecución de Resoluciones Extranjeras, documento que se aprobó en La Haya el 2 de julio de 2019 en la sesión diplomática. En la Convención de alimentos yo participé desde la primera sesión plenaria hasta la reunión diplomática, en la firma ad-referendum, en esa sesión hubo un gran atención hacia mí, porque normalmente en las negociaciones participan los representantes de los países y al momento de la firma se presenta el embajador y los representantes que habían negociado ya no intervenían, conmigo la Embajada de México tuvo una gran deferencia, el embajador no asistió a la sesión diplomática, yo supuse que quien asistió en su representación sería quien firmará, no fue así, cuando tocó el turno de México se me dijo: usted firma, eso para mí fue un detalle muy delicado del embajador y un gran honor como mexicana.

AUB: Claro, una gran responsabilidad con respecto a las decisiones en materia de derecho internacional privado. Doctora, en ese 
mismo sentido siguiendo la línea del derecho internacional privado permítame pedirle que nos explique cuál es el problema del sistema actual internacional de solución de conflictos de leyes por convergencia de normas jurídicas, ¿qué situación tenemos actualmente en México? las problemáticas con respecto a este sistema tradicional ¿ha beneficiado o no ha beneficiado? En el Derecho Internacional Privado ¿sería adecuado tal vez considerar el conformar una conferencia en América Latina para homologar nuestras normas conflictuales?

MEMM: En realidad casi todos los países tienen el mismo tipo de normas conflictuales, lo que cambia es el principio que rige al país; que es el principio de domicilio o el de nacionalidad, hay una Convención de La Haya que armoniza estos dos principios, sin embargo el sistema conflictual continuará aplicándose. Las normas de conflicto en realidad son reglas matemáticas, si se conocen y aplican correctamente, el conflicto se resuelve, el problema se presenta por lo diferente del principio que se aplica, por ejemplo México aplica el principio de domicilio, Francia aplica nacionalidad ahí puede surgir el reenvió negativo o el reenvío positivo que por cierto, el reenvío positivo no existe porque no hay reenvío, el derecho de los dos países es aplicable al conflicto. La convención de la que México no es parte, creada por la Haya comprende solo, seis articulitos y resuelve el problema que deriva de los principios de domicilio y nacionalidad. El sistema conflictual tradicional nunca dejará de aplicarse porque es como los principios generales del derecho que cubren las lagunas legales, las convenciones eliminan muchos de esos problemas, por ser un derecho uniforme, la reciprocidad también va a solucionar parte de los conflictos La última convención aprobada en la Conferencia de La Haya es sobre Acuerdos de Elección de Foro ratificada solo por México y por la Unión Europea, por lo tanto tenemos acuerdos de elección de foro con más de veinte países. 
Lo mismo ocurre con otras convenciones, lo importante es que los países las ratifiquen y poco a poco se implementará un derecho uniforme.

Está el Código de Bustamante de 1928, es un documento que regula la materia de Derecho Internacional Privado en todas las ramas, aplicarlo sería ideal. México actualmente tiene en estudio una ley de derecho internacional privado, en noviembre será el LXII Seminario de Derecho Internacional Privado y Comparado, en él se va a presentar el proyecto. Hay muchos países que ya tienen una ley sobre Derecho Internacional Privado por lo tanto sería ideal que en América Latina también tuviéramos uno.

AUB: Doctora quiero tocar un tema de una forma muy breve, el problema referente a la cooperación internacional, ahora que nos enfrentamos a algunas situaciones con la globalización en torno al exhorto internacional, a la extradición, con los recientes problemas que se han presentado incluso hablando de crimen organizado y donde tenemos estas problemáticas ¿hasta dónde México podría interferir en algunos procesos de extradición?

MEMM: No estoy de acuerdo en extraditar a los nacionales, porque eso implica decir "yo no puedo juzgar, yo no puedo aplicar mi derecho". En general los países no extraditan a sus nacionales y nosotros no extraditábamos, ahora lo hemos hecho, esto es como llevar a su hijo a que lo castigue el vecino porque le rompió el cristal, obviamente no lo hará porque es usted quien debe decidir si castigar o no al niño, a usted le corresponde esa responsabilidad, es claro que se debe sancionar, pero debe ser en su país con su propio derecho.

AUB: Doctora no quiero excederme tampoco en el tiempo y primero quisiera saber si usted podría hacernos alguna recomendación para todos los que están interesados en el derecho internacional privado y quisieran conocer su obra, ¿hay alguna sugerencia de libro de su autoría que pudiera iniciarnos en el derecho internacional privado? 
MEMM: Yo en eso soy muy modesta, siempre les digo a mis alumnos vayan a la biblioteca y busquen los libros de internacional privado, hay muchos, nunca menciono el mío. El primer curso lo publicó la editorial iure, la que me preguntó si podría ofrecerlo en mis grupos, a lo que yo me opuse, para evitar que mis alumnos se sintieran obligados a adquirirlo y eso es muy penoso. Esta obra inicialmente comprendía dieciséis unidades, la Secretaría Académica me solicitó que redujera el programa a diez, lo hice, sin embargo el libro ya estaba para segunda edición por lo tanto continua con dieciséis unidades, debido a que lo envié antes del cambio solicitado.

El segundo curso lo realicé para la enciclopedia de la Facultad, no requiere cambio ni actualización porque contiene las principales convenciones con su respectivo análisis y comentarios. Sobre la asignatura de Derecho Internacional Privado hay muy buenos libros mexicanos, está el del Doctor. Pérez Nieto, el del Doctor Arellano García y el del Maestro Contreras Baca y por supuesto los clásicos que siempre hay que consultar.

AUB: ¿Cuál es el título de su libro doctora?

MEMM: Derecho Internacional Privado, tanto el de Iure que es el primer curso, como el de la enciclopedia, solo que el de la enciclopedia tiene Derecho Internacional Privado volumen 1 y Derecho Internacional Privado volumen 2 los dos corresponden al segundo curso.

AUB: Me ha encantado de verdad escucharla pero esto debe tener un fin, entonces no quiero terminar la entrevista sin preguntarle doctora si tiene alguna sugerencia para los nuevos juristas aquellos juristas que se están formando que están tratando de encontrar su camino en el derecho, ¿hay alguna sugerencia para ellos que usted pudiera darnos?

MEMM: Yo les destaco siempre que las cualidades del abogado, son la puntualidad, la responsabilidad la presentación y la preparación pero además les aclaró que, en el Derecho Internacional Priva- 
do nunca les va a faltar trabajo, van a vivir muy bien porque es un área poco competida y muy generosa.

AUB: La verdad es que ha sido un gran placer escucharla, quisiera despedirme de usted por supuesto pidiéndole que en algún otro momento pudiéramos retomar alguna entrevista y volverla a escuchar, si es que así su agenda lo permite. No queremos dejar las puertas cerradas con usted sino al contrario agradecerle por esta entrevista, la cuál ha sido muy enriquecedora, le agradezco infinitamente de parte de la revista esta entrevista.

MEMM: Doctora Uscanga, le agradezco muchísimo el haber pensado en mí para esta entrevista. Desde luego puertas abiertas, yo nunca tengo puertas cerradas y mucho menos para usted que la conozco desde hace un buen tiempo, conozco su trayectoria, como ha ido desarrollándose y preparándose, estas puertas siempre estarán abiertas para usted.

AUB: Gracias doctora, muchísimas gracias de nuevo.

MEMM: A usted, muchas gracias. 